\title{
BMJ Open How many infants may have died in low-income and middle-income countries in 2020 due to the economic contraction accompanying the COVID-19 pandemic? Mortality projections based on forecasted declines in economic growth
}

Gil Shapira (D) , Damien de Walque (D), Jed Friedman (D)

To cite: Shapira G, de Walque D, Friedman J. How many infants may have died in low-income and middle-income countries in 2020 due to the economic contraction accompanying the COVID-19 pandemic? Mortality projections based on forecasted declines in economic growth. BMJ Open 2021;11:e050551. doi:10.1136/ bmjopen-2021-050551

- Prepublication history and additional supplemental material for this paper are available online. To view these files, please visit the journal online. (http://dx.doi.org/10.1136/ bmjopen-2021-050551).

Received 22 February 2021 Accepted 02 August 2021

\section{D) Check for updates}

(C) Author(s) (or their employer(s)) 2021. Re-use permitted under CC BY-NC. No commercial re-use. See rights and permissions. Published by BMJ.

Development Research Group, World Bank, Washington, Columbia, USA

Correspondence to

Dr Gil Shapira;

gshapira@worldbank.org

\section{ABSTRACT}

Objectives While COVID-19 has a relatively small direct impact on infant mortality, the pandemic is expected to indirectly increase mortality of this vulnerable group in low-income and middle-income countries through its effects on the economy and health system performance. Previous studies projected indirect mortality by modelling how hypothesised disruptions in health services will affect health outcomes. We provide alternative projections, relying on modelling the relationship between aggregate income shocks and mortality.

Design We construct a sample of 5.2 million births by pooling retrospective birth histories reported by women in Demographic and Health Surveys conducted in 83 low-income and middle-income countries between 1985 and 2018. We employ regression models with countryspecific fixed-effects and flexible time trends to estimate the impact of gross domestic product per capita on infant mortality rate. We then use growth projections by the International Monetary Fund to predict the effect of the economic downturn in 2020 on infant mortality.

Results We estimate 267208 (95\% Cl 112000 to 422 415) excess infant deaths in 128 countries, corresponding to a $6.8 \%(95 \% \mathrm{Cl} 2.8 \%$ to $10.7 \%)$ increase in the total number of infant deaths expected in 2020.

Conclusions The findings underscore the vulnerability of infants to the negative income shocks such as those imposed by the COVID-19 pandemic. While efforts towards prevention and treatment of COVID-19 remain paramount, the global community should also strengthen social safety nets and assure continuity of essential health services.

\section{INTRODUCTION}

Reducing morality risk in the wake of the COVID-19 pandemic is a paramount public concern. While direct mortality risk as a result of COVID-19 infection has garnered the majority of attention in global media and policy discussions, indirect mortality
Strengths and limitations of this study

- Our study links gross domestic product (GDP) per capita data to an especially large dataset of 5.2 million retrospective birth histories reported in Demographic and Health Surveys conducted in many low-income and middle-income countries between 1985 and 2018.

- While previous projections of indirect COVID-19 mortality have been based on assumptions regarding the magnitude of health service disruptions, our estimates account for additional mechanisms, mainly increased household poverty.

- Our estimates may represent a lower bound of the actual excess mortality if the current economic downturn is accompanied by larger disruptions to the provision of essential health services relative to previous downturns.

- We estimate the short-term impact of GDP fluctuations on mortality while long-term implications for mortality and other adverse outcomes may also arise.

- The analysis ascribes the difference between October 2019 and October 2020 economic growth projections for 2020 solely to the pandemic, even though some countries have also experienced other shocks, such as natural disasters or political crises that may affect national income levels.

may be substantial. Health and social policies should not lose sight of excess indirect mortality caused by such factors as the interruption of essential health services and the general economic downturn brought on by the pandemic. This study attempts to quantify the expected indirect mortality over the pandemic period for one especially vulnerable subpopulation-infants-by modelling 
the impact of projected economic decline on the likelihood of infant survival.

Studies from diverse settings find negligible direct mortality rates for children and infants due to COVID19. ${ }^{1}$ However, stringent containment measures and the ensuing economic downturn, as well as the need to reallocate health system resources towards pandemic response, have influenced many social determinants of mortality such as the ability to afford nutritious foods and to access essential healthcare. Unlike economic crises in high-income countries, which appear to lower mortality, ${ }^{2}$ economic crises in low-income countries generally increase mortality among vulnerable groups, namely young children and the elderly. Earlier studies have documented a robust relationship between short-term fluctuation in aggregate income and all-cause infant mortality in low-income and middle-income countries..$^{3-8}$

At the very start of the COVID-19 pandemic, modelling exercises predicted that the interruption of essential health services will be severe $e^{9-1412}$ and perhaps the world will experience 250000 to 1.15 million young child deaths ${ }^{15}$ in the first 6 months of the pandemic. Recent studies indicate that barriers to access essential healthcare in low-income and middle-income countries are not just a theoretical concern documenting, for example, disruptions in immunisation services in Pakistan and Sierra Leone ${ }^{1617}$ and access to primary care in sub-Saharan Africa. ${ }^{18}{ }^{19}$ At the same time, the global economy is expected to contract $4.9 \%$ in the first year of the pandemic ${ }^{20}$ and the global poverty headcount is projected to increase by 120 million people. ${ }^{21}$ Based on historical data, this economic decline is likely to be associated with higher mortality in excess of COVID-19 fatalities, ${ }^{22}$ especially in low-income and middle-income economies, and will create food insecurity ${ }^{23}$ and lower the affordability among vulnerable households of key goods and services necessary for child survival.

In this study, we estimate the impact of the economic downturn on infant mortality by modelling the relationship between GDP fluctuations and infant mortality, following the approach of Baird et al. ${ }^{5}$ We link GDP per capita data to 5.2 million retrospective birth histories reported in 83 Demographic and Health Surveys (DHS) conducted in low-income and middle-income countries between 1985 and 2017. Then, we use growth projections by International Monetary Fund (IMF) World Economic Outlook (WEO) to predict the effect of the economic downturn in 2020 on infant mortality.

\section{DATA AND METHODS}

To estimate the impact of changes in aggregate income on infant mortality, we rely on two sources of data. Data on GDP per capita is taken from the World Development Indicators. We use values adjusted for purchasing power parity, corresponding to 2011 US dollars. Data on infant mortality are constructed from retrospective birth history reports in all DHS conducted in 83 low-income and middle-income countries between 1985 and 2018. The surveys used in the analysis are listed in online supplemental appendix table A1. The combined sample totals 5.2 million births, of which $27 \%$ and $55 \%$ are from lowincome and lower-middle-income countries. Over the full period of analysis, the sample's infant mortality rate per 1000 births is 85, 61 and 37 for low-income, lower-middleincome and upper-middle-income countries, respectively.

We estimate the relation between aggregate income change and infant mortality with the following framework:

$$
\mathrm{D}_{\mathrm{ict}}=\alpha_{\mathrm{c}}+\beta \log \mathrm{GDP} \mathrm{P}_{\mathrm{ct}}+\gamma_{1 \mathrm{c}} \mathrm{t}_{\mathrm{ct}}+\gamma_{\mathrm{ct}} \mathrm{t}_{\mathrm{ct}}^{2}+\gamma_{\mathrm{sc}} \mathrm{t}_{\mathrm{ct}}^{3}+\varepsilon_{\mathrm{ict}}
$$

$D_{i c t}$ is a binary indicator taking the value 1 if child $i$ in country $c$ died in the first 12 months of life during year $t$. $\log G D P$ is the natural logarithm of per capita GDP and $\varepsilon_{\text {iact }}$ is the error term. The $\alpha$ and $\gamma$ coefficients identify countryspecific fixed effects and a country-specific cubic time trend, respectively. SEs are clustered at the country level; $\beta$ is the coefficient of interest, describing the relationship between aggregate income shocks and infant mortality. We estimate this semi-elasticity of infant mortality to aggregate income decline separately by country income level, as classified by the World Bank 2020 income groups, as well as overall. Low-income economies are defined by a gross national income (GNI) per capita of $<$ US $\$ 1035$ in 2019. Lower middle-income economies are defined by a GNI between US $\$ 1036$ and US $\$ 4045$ and the range for upper-middle-income economies is between US\$4046 and US\$12535. To explore the robustness of the findings, both we and Baird et al find appreciably similar results with linear or quadratic time trends, as well as alternative recall periods for births ( 5 or 15 years as opposed to the default 10 years).

As a projection of the aggregate income shock in each country, we compare growth predictions for the same calendar period made before and then during the pandemic. Specifically, we use the IMF WEO 2020 growth rates projected in October 2019 and in October 2020. We define the difference between the two projections as the growth shortfall that is likely attributed to the pandemic and the ensuing economic crisis. Between October 2019 and October 2020, the IMF revised downwards the growth projections for all countries. The average shortfall for low-income and middle-income countries is $9.3 \%$. The average projected shortfall in low-income countries, $5.9 \%$, is less than half of the projected average shortfall in upper-middle-income countries, $12.5 \%$.

To calculate the number of excess infant deaths that were likely caused by the pandemic in each country, we multiply the projected growth shortfalls with the $\beta$ coefficient from the regression specification above. We then multiply by the projected number of births in each country, taken from the United Nation's World Population Prospects 2019. The total number of births are projected for the 5-year period 2015-2020 and we assume equal proportion of births for each year (the projections are available at population.un.org/wpp). 
Table 1 Estimated relationship between aggregate income shocks and infant mortality rate per 1000 children, by World Bank country income groups

\begin{tabular}{llll}
\hline $\begin{array}{l}\text { Low-income } \\
\text { countries }\end{array}$ & $\begin{array}{l}\text { Lower-middle-income } \\
\text { countries }\end{array}$ & $\begin{array}{l}\text { Upper-middle-income } \\
\text { countries }\end{array}$ & $\begin{array}{l}\text { Low-income and middle-income } \\
\text { countries }\end{array}$ \\
\hline$-47.85^{\star \star \star}$ & $-23.73^{\star \star \star}$ & $-16.08^{\star \star \star}$ & $-23.12^{\star \star \star}$ \\
$(17.71)$ & $(5.50)$ & $(6.80)$ & $(9.38)$ \\
\hline
\end{tabular}

Overall number of observed births is 5273350 . The table presents coefficient estimates from regressions of infant mortality log per capita GDP with time trends and country fixed effects. SEs are presented in parentheses. There are four income groupings for countries; the country income groups follow the World Bank classification for fiscal year 2021.

Source: authors' estimation using data from Demographic and Health Surveys and World Development Indicators.

${ }^{*} \mathrm{P}<0.10,{ }^{* *} \mathrm{p}<0.05,{ }^{* * *} \mathrm{p}<0.01$.

\section{Patient and public involvement}

The study presents analysis of secondary data. There was no patient and public involvement.

\section{RESULTS}

\section{Estimation of the GDP-mortality relationship}

The regression coefficient estimates are presented in table 1 . A $1 \%$ decrease in GDP per capita is associated with a 0.23 increase in infant mortality per 1000 children born in low-income and middle-income countries. These estimates vary substantially by income group. A $1 \%$ decrease in per capita GDP is associated with increases of $0.48,0.24$ and 0.16 in infant mortality per 1000 children born in low-income, lower-middle-income and uppermiddle-income countries, respectively.

Our estimate for the relationship between GDP and infant mortality is significantly lower than the estimate presented in the study by Baird et al, using the same specification. ${ }^{5}$ This previous analysis estimated that a $1 \%$ decrease in GDP per capita is associated with a 0.40 increase in infant mortality per 1000 children born in low-income and middle-income countries. Two things might drive this difference. First, we have a different composition of countries given that more DHS datasets are available. Our analysis includes 83 countries relative to 59 in the earlier paper. Second, resiliency to income shocks may have improved over time through increased household incomes and more developed health systems.

\section{Projection of excess infant mortality in $\mathbf{2 0 2 0}$}

In table 2, we report the estimated excess infant mortality in 128 low-income and middle-income countries, along with $95 \% \mathrm{CI}$ around the estimate. The results by income group and region presented in table 2 are aggregations of the country-level projections presented in online supplemental appendix table A2. In total, we estimate 267208 (112 000-422 415) excess infant deaths in lower-income and middle-income countries due to the growth shortfall in 2020. Most of the excess mortality is estimated to occur in the 46 lower-middle-income countries, even though the income mortality semi-elasticity in low-income countries is almost twice the size of that in lower-middleincome countries. This is explained both by the fact that there are more countries and more populous countries in the lower-middle-income countries group and because the IMF projects larger growth shortfalls in that group. It is worth noting than more than a third of the excess infant mortality is projected to be in India (99 642). India has the highest number of annual births (24 238000$)$ as well as a particularly large projected economic shortfall of $-17.3 \%$. Because of this, South Asia is the region with the highest expected excess infant mortality, although there are only eight countries included in the analysis. Nigeria

Table 2 Projected excess infant deaths with 95\% Cls, by World Bank country income groups and regions

\begin{tabular}{|c|c|c|c|}
\hline & Estimate & $95 \% \mathrm{Cl}$ & Countries \\
\hline Total & 267208 & 112000 to 422415 & 128 \\
\hline \multicolumn{4}{|l|}{ By income group } \\
\hline $\begin{array}{l}\text { Low-income } \\
\text { economies }\end{array}$ & 65628 & 18013 to 113241 & 29 \\
\hline $\begin{array}{l}\text { Lower-middle- } \\
\text { income } \\
\text { economies }\end{array}$ & 158638 & 86646 to 230628 & 46 \\
\hline $\begin{array}{l}\text { Upper-middle- } \\
\text { income } \\
\text { economies }\end{array}$ & 42942 & 7340 to 78544 & 53 \\
\hline
\end{tabular}

By region

\begin{tabular}{lrlc}
$\begin{array}{l}\text { Sub-Saharan } \\
\text { Africa }\end{array}$ & 82239 & 29198 to 135280 & 48 \\
$\begin{array}{l}\text { East Asia and } \\
\text { Pacific }\end{array}$ & 32537 & 12899 to 52174 & 19 \\
$\begin{array}{l}\text { Europe and } \\
\text { Central Asia }\end{array}$ & 7962 & 2372 to 13553 & 20 \\
$\begin{array}{l}\text { Latin America } \\
\text { and the } \\
\text { Caribbean }\end{array}$ & 17202 & 3628 to 30776 & 23 \\
$\begin{array}{l}\text { Middle East } \\
\text { and North }\end{array}$ & 14127 & 4067 to 24187 & 10 \\
$\begin{array}{l}\text { Africa } \\
\text { South Asia }\end{array}$ & 113141 & 59836 to 166446 & 8 \\
\hline
\end{tabular}

The definitions of income groups and regions are based on the World Bank country group categorisation for the 2021 fiscal year.

Source: authors' projections based on estimated parameters presented in table 1 and data from International Monetary Fund World Economic Outlook and World Population Prospects. 
and China are a distant second and third with projected excess infant deaths of 11904 and 10835.

To benchmark our projections of excess infant deaths, we assess the percentage increase in infant mortality these additional deaths represent. To that end, we calculate the expected infant mortality in the absence of the pandemic for the 128 countries. According to the World Bank's World Development Indicators, estimated infant mortality rates in low-income, lower-middle-income and uppermiddle-income countries were 48, 37 and 11 deaths per 1000 live births, respectively in 2019. We multiply these rates by the annual number of births in each country to forecast a total of 3953466 deaths. Assuming that infant mortality rate in 2020 would have been similar to that in 2019 if the COVID-19 outbreak has not occurred, the excess deaths we project correspond to an increase of $6.8 \%$ (95\% CI $2.8 \%$ to $10.7 \%$ ) in the total number of expected infant deaths.

\section{DISCUSSION}

In this study, we have assessed the potential impact of the 2020 economic downturn caused by the COVID-19 pandemic on infant mortality-we estimate almost 270000 excess infant deaths in the 12 months following the start of the pandemic. A useful comparison point to this estimate is the 28000-50000 excess infant deaths estimated for Africa after the financial crisis in 2009. ${ }^{7}$ Our Africa estimate in 2020 is 82239 (95\% CI 37858 to 126 620) infant deaths. This higher projection reflects the larger estimated GDP shortfalls. Several mechanisms are likely driving this increase in mortality among children $0-1$ year of age: impoverishment at the household level will lead to worse nutrition and care practices for infants and reduced ability to access health services, while the economic crisis might also affect the supply and quality of services offered by the health systems. ${ }^{19}$ It is difficult to compare our estimates with other projections focusing on health system disruption as the main driver as the methodology, the age ranges and the time period are different. The most comparable study, with a focus on child mortality, predicts 253500-1 157000 additional under-5 child deaths over the first 6 months of the pandemic, depending on the scenario severity. ${ }^{15}$

Our estimates of excess infant mortality are not additional to previous projections but serve as an alternative. Our reduced form approach yields estimates that already incorporate at least some consequences of reduced utilisation of health services, that is, those reductions that have historically arose during severe economic downturns. Our estimates also directly account for other mechanisms, mainly increased poverty. As past economic crises were not driven by a pandemic, it is possible that the world will experience a higher indirect mortality shock than implied by the historic income-mortality semielasticity if the current economic downturn is accompanied by more severe disruptions to the supply of effective health services. Therefore, our projections may provide a lower bound of actual indirect mortality. On the other hand, the projections reported in this paper ascribe the difference between the WEO October 2019 and October 2020 economic growth projections for 2020 solely to the pandemic, even though some countries have also experienced other shocks, such as natural disasters or political crises.

Regarding limitations of the analysis, one refinement of our estimation approach would consider the relevant expenditure categories that directly determine the production of child health, rather than overall expenditure as captured in GDP. Relevant expenditure categories include public health sector spending, private spending on health and nutrition, foreign assistance in the form of health aid and public and private spending on related sectors and services such as water and sanitation. It is these components of GDP that are more directly tied to child survival and would likely exhibit a more predictive relationship to infant mortality than overall GDP exhibits. Unfortunately, these more granular data do not exist in a systematic and standardised form for the countries and time periods considered, nor are there standard future projections of such components. Therefore, we follow the existent literature and explore the relation between a widespread summary measures of national economic output, GDP, and infant survival.

An extension of our approach may also consider country characteristics that likely mediate the GDP-mortality relation, including measures of economic inequality. Infant mortality in more unequal countries is likely more vulnerable to economic contractions. However, here again, we do not have the necessary annual data to easily include a summary inequality measure such as the Gini coefficient within our estimation framework. The DHS allow us to construct annual birth and mortality indicators from retrospective reports of fertility yet do not include per capita consumption or wealth status for the same years. Standard cross-country datasets such as PovCalNet ( iresearch.worldbank.org/PovcalNet/index.htm) update the national Gini coefficient only on a sporadic basis. For example, the Gini estimate for India is only updated for the years 1987, 1993, 2004, 2009, and 2011.

Another limitation of our analysis is that it relies on retrospective birth histories in DHS. In the absence of comprehensive and robust vital registration statistics in most of the countries included in this analysis, this is likely the most comprehensive data source available. However, such household survey data can be affected by recall bias, especially for birth and deaths occurring long before the survey date. For this reason, we have explored the stability of estimates to alternative birth recall periods and find appreciably similar results. Another limitation is that we only consider the short-term impact of GDP fluctuations on mortality while long-term consequences might also exist. Long-term impacts on the number of infant deaths could also occur through changes in fertility behaviour but should not affect our projections for 2020. Although COVID-19 was first detected in the end of 2019, the 
outbreak was declared a pandemic only in March 2020. If there were impacts on fertility, they would impact births and infant mortality in 2021. Finally, economic contractions in high-income countries might reduce foreign aid to lower-income countries which in turn can increase mortality. ${ }^{24}$ If declining aid affects future GDP, our model does not account for such mechanisms as we assume that a country's infant mortality rate is only affected by its (own) contemporaneous GDP.

Regarding the reported CIs for projected excess infant deaths in table 2, note that these bounds may be regarded as conservative. This is because we first apply the 5 th percentile lower bound and then the 95 th percentile upper bound estimate of the mortality semi-elasticity to the projected growth contractions for all countries in order to estimate the bounds. This exercise implicitly imposes a perfect correlation of semi-elasticities across countries. If instead, each country receives its own independent draw from the distribution of semi-elasticities then there will be significantly tighter confidence bounds, at least in expectation.

On the other hand, there may also be forecast error in either the country-level economic growth projections or in the projections of number of births. These potential errors are not directly modelled. Previous literature suggests these forecast errors have an expected mean of zero, with most deviations from forecast on the order of \pm 1 percentage point of economic growth or $\pm 3 \%$ of total births. ${ }^{2526}$ To explore further the role of uncertainty in economic and demographic projections, we consider Monte Carlo simulations that model countryspecific growth and birth projections with a slightly larger anticipated degree of error. Specifically, we simulate a draw for each country from growth projections that are uniformly distributed around the projection at \pm 1.5 percentage points and draws for the birth projection that are uniformly distributed around the projection at $\pm 4 \%$. After 10000 simulations, we obtain a $95 \%$ CI of total excess deaths to be (251 588 to 283106 ), substantially narrower than the reported CI of (112 000 to 422415 ). This suggests that uncertainty in the true value of the growth-IMR semi-elasticity is the most influential parameter driving uncertainty in the projected total number of indirect infant deaths.

Regardless of the exact number of projected deaths, the large number of excess infant deaths estimated in our analysis underscores the vulnerability of this age group to negative aggregate income shocks such as those induced by the COVID-19 pandemic. While we focused on the $0-1$ age group, our estimates are suggestive of other vulnerabilities not directly attributable to COVID-19 among other segments of the population such as children aged 1-5 years, pregnant women and the elderly. As countries, health systems and the wider global community continue efforts to prevent and treat COVID-19, we should also consider resources to stabilise health systems and strengthen social safety nets in order to mitigate the human, social and economic consequences of the pandemic and related lockdown policies.

Acknowledgements We gratefully acknowledge the excellent support provided by Salome Drouard as a research assistant. The findings, interpretations and conclusions expressed in this paper are entirely those of the authors and do not necessarily represent the views of the World Bank, its executive directors, of the governments of the countries they represent.

Contributors The study and the methodology were conceived by all authors. GS conducted the formal analysis. GS and JF validated the results. All authors collaborated on writing the paper.

Funding The authors have not declared a specific grant for this research from any funding agency in the public, commercial or not-for-profit sectors.

Competing interests None declared.

Patient consent for publication Not required.

Ethics approval Ethics approval was not sought as the study presents results of an analysis of secondary data and does not involve human participants.

Provenance and peer review Not commissioned; externally peer reviewed.

Data availability statement Data may be obtained from a third party and are not publicly available. Requests to access the data can be submitted on the Demographic and Health Surveys Program at dhsprogram.com.

Supplemental material This content has been supplied by the author(s). It has not been vetted by BMJ Publishing Group Limited (BMJ) and may not have been peer-reviewed. Any opinions or recommendations discussed are solely those of the author(s) and are not endorsed by BMJ. BMJ disclaims all liability and responsibility arising from any reliance placed on the content. Where the content includes any translated material, BMJ does not warrant the accuracy and reliability of the translations (including but not limited to local regulations, clinical guidelines, terminology, drug names and drug dosages), and is not responsible for any error and/or omissions arising from translation and adaptation or otherwise.

Open access This is an open access article distributed in accordance with the Creative Commons Attribution Non Commercial (CC BY-NC 4.0) license, which permits others to distribute, remix, adapt, build upon this work non-commercially, and license their derivative works on different terms, provided the original work is properly cited, appropriate credit is given, any changes made indicated, and the use is non-commercial. See: http://creativecommons.org/licenses/by-nc/4.0/.

ORCID iDs

Gil Shapira http://orcid.org/0000-0002-1138-7269

Damien de Walque http://orcid.org/0000-0003-1592-7602

Jed Friedman http://orcid.org/0000-0002-6763-5890

\section{REFERENCES}

1 Levin A, Meyerowitz-Katz G, Owusu-Boaitey N. Assessing the age specificity of infection fatality rates for COVID-19: systematic review, meta-analysis, and public policy implications. Eur J Epidemiol 2020:1-16.

2 Ruhm CJ. Health effects of economic crises. Health Econ 2016;25 Suppl 2:6-24.

3 Pritchett L, Summers LH. Wealthier is healthier. J Hum Resour 1996;31:841-68.

4 Bhalotra S. Fatal fluctuations? Cyclicality in infant mortality in India. $J$ Dev Econ 2010;93:7-19.

5 Baird S, Friedman J, Schady N. Aggregate income shocks and infant mortality in the developing world. Rev Econ Stat 2011;93:847-56.

6 Cruces G, Glüzmann P, Calva LFL, López LF. Economic crises, maternal and infant mortality, low birth weight and enrollment rates: evidence from Argentina's downturns. World Dev 2012;40:303-14.

7 Friedman J, Schady N. How many infants likely died in Africa as a result of the 2008-2009 global financial crisis? Health Econ 2013;22:611-22.

8 Maruthappu M, Watson RA, Watkins J, et al. Effects of economic downturns on child mortality: a global economic analysis, 1981-2010. BMJ Glob Health 2017;2:e000157. doi:10.1136/ bmjgh-2016-000157

9 Abbas K, Procter SR, van Zandvoort K, et al. Routine childhood immunisation during the COVID-19 pandemic in Africa: a benefitrisk analysis of health benefits versus excess risk of SARS-CoV-2 infection. Lancet Glob Health 2020;8:e1264-72. 
10 Hogan AB, Jewell BL, Sherrard-Smith E, et al. Potential impact of the COVID-19 pandemic on HIV, tuberculosis, and malaria in low-income and middle-income countries: a modelling study. Lancet Glob Health 2020;8:e1132-41.

11 Jewell BL, Mudimu E, Stover J, et al. Potential effects of disruption to HIV programmes in sub-Saharan Africa caused by COVID-19: results from multiple mathematical models. Lancet HIV 2020;7:e629-40.

12 Sherrard-Smith E, Hogan AB, Hamlet A, et al. The potential public health consequences of COVID-19 on malaria in Africa. Nat Med 2020;26:1411-6.

13 World Health Organization. Pulse survey on continuity of essential health services during the COVID-19 pandemic, 2020.

14 Kotlar B, Gerson E, Petrillo S, et al. The impact of the COVID-19 pandemic on maternal and perinatal health: a scoping review. Reprod Health 2021;18:10.

15 Roberton T, Carter ED, Chou VB, et al. Early estimates of the indirect effects of the COVID-19 pandemic on maternal and child mortality in low-income and middle-income countries: a modelling study. Lancet Glob Health 2020;8:e901-8.

16 Chandir S, Siddiqi DA, Mehmood M, et al. Impact of COVID-19 pandemic response on uptake of routine immunizations in Sindh, Pakistan: an analysis of provincial electronic immunization registry data. Vaccine. 2020;38:7146-55.

17 Buonsenso D, Cinicola B, Kallon MN, et al. Child healthcare and immunizations in sub-Saharan Africa during the COVID-19 pandemic. Front Pediatr 2020;8:517.
18 Siedner MJ, Kraemer JD, Meyer MJ, et al. Access to primary healthcare during lockdown measures for COVID-19 in rural South Africa: an interrupted time series analysis. BMJ Open 2020;10:e043763.

19 Shapira G, Ahmed T, Drouard SHP, et al. Disruptions in maternal and child health service utilization during COVID-19: analysis from eight sub-Saharan African countries. Health Policy Plan 2021. doi:10.1093/ heapol/czab064. [Epub ahead of print: 19 Jun 2021].

20 International Monetary Fund. World economic outlook, October 2020: a long and difficult ascent, 2020.

21 Lakner C, Yonzandaniel N, Mahlerr G, et al. Updated estimates of the impact of COVID-19 on global poverty: looking back at 2020 and the outlook for 2021, 2021.

22 Doerr S, Hofmann B. The recession-mortality nexus and COVID-19. Bank of International Settlements, 2020.

23 Egger D, Miguel E, Warren SS, et al. Falling living standards during the COVID-19 crisis: quantitative evidence from nine developing countries. Sci Adv 2021;7. doi:10.1126/sciadv.abe0997. [Epub ahead of print: 05 Feb 2021].

24 Kabir M, Saqib MAN, Zaid M, et al. COVID-19, economic impact and child mortality: a global concern. Clin Nutr 2020;39:2322-3.

25 Eicher TS, Kuenzel DJ, Papageorgiou C, et al. Forecasts in times of crises. Int J Forecast 2019;35:1143-59.

26 Nico Keilman. Data quality and accuracy of United Nations population projections. Demography;55:149-64. doi:10.1080/00324720127686 